\title{
Fundamentos constitucionales de la economía social de mercado en la economía peruana
}

Abg. Milagros K. Olivos Celis*

\section{RESUMEN}

La Constitución Política del Perú de 1993 reconoce que la sociedad económica peruana se rige por los principios de una Economía Social de Mercado, entendida como una condición sine qua non de un Estado Social y Democrático de Derecho, y que pretende ser compatible con los fundamentos axiológicos y teleológicos inspiradores del mismo Estado. En tal sentido, el Estado asume como función esencial orientar el desarrollo del país a través de mecanismos que permitan a los agentes del mercado actuar de forma libre, al tiempo que protege a los consumidores y garantiza la competencia. Es decir, constitucionalmente se reconoce la presencia de un modelo económico que tiene como principio fundamental el respeto a las libertades económicas, pero que está al servicio de la persona.

El presente artículo tiene como finalidad esencial realizar un análisis doctrinario, legal y jurisprudencial de la Economía Social de Mercado y de las funciones de un Estado regulador que proteja los intereses de la vida en sociedad, orientado a determinar los lineamientos que debe seguir dicho Estado en su actividad reguladora.

La estructura de este análisis parte por plantear algunas consideraciones conceptuales de los modelos económicos tradicionales, a fin de determinar cuáles son las características del modelo intermedio que se gestó en Alemania de la post guerra [la Economía Social de Mercado], modelo que luego fue adoptado por diversos países del mundo, entre ellos Perú, quien a partir de 1979 comienza con sus primeras configuraciones y hasta 1993 cuando comienza su apogeo legal, jurisprudencial y doctrinario.

\section{PALABRAS CLAVES}

Modelo Económico, Economía Social de Mercado, Constitución Económica, Libertades Económicas. 


\section{SUMARIO}

1. A modo introducción: primeras configuraciones del Régimen Económico de la Constitución de 1993. 2. Los Sistemas Económicos Tradicionales. 3. Surgimiento de un nuevo modelo económico: Economía Social de Mercado. 4. Régimen Económico Peruano según la Constitución Política del Perú de 1993. 4.1. Marco normativo constitucionalmente reconocido. 4.2. Pilares de la Economía Social de Mercado en la CPP de 1993. 5. Facultades del Estado en regulación económica. 6. Derecho y Economía: La relación entre el deber de garantizar las libertades económicas y el rol regulador del estado. 7. Bibliografía.

\section{A MODO INTRODUCCIÓN: PRIMERAS CONFIGURACIONES DEL RÉGIMEN ECONÓMICO DE LA CONSTITUCIÓN DE 1993}

En los últimos años la economía nacional ha demostrado un crecimiento acelerado y ha llegado a convertirse en un gran atractivo, no sólo para el inversionista local, sino también para el extranjero. Dicha situación ha generado que los temas del derecho económico cobren especial relevancia y comiencen a plantearse algunas reflexiones en torno a sus fundamentos.

A nivel constitucional, nuestra Carta Magna reconoce que el Perú se rige por los pilares de una Economía Social de Mercado, novedad que viene desde 1979; no obstante, es a partir de la década de los noventa, cuando la conciencia sobre la importancia del reconocimiento de ciertos derechos con contenido económico toma mayor fuerza. De manera expresa, el Preámbulo del Texto Constitucional del 79' se hace referencia a la necesidad de una sociedad justa donde la economía esté al servicio del hombre y no el hombre al servicio de la economía, siendo el artículo $115^{\circ}$ el que precisa que "[...] la iniciativa privada es libre. Se ejerce en una Economía Social de Mercado. El Estado estimula y reglamenta su ejercicio para armonizarlo con el interés social”. Es decir, desde aquella época se pretendía considerar el aspecto social de la inversión pública.

Sin embargo es hasta 1993 que el constituyente creyó necesario que la legislación tenga por objeto esencial establecer "reglas de juego" claras para los procesos económicos que garanticen la libertad, y que a la vez sean reflejo de valores democráticos, cuya práctica sea eficiente. A partir de esa fecha las primeras manifestaciones de la vida económica peruana que surgieron años atrás se consolidarían en valores, principios y libertades que se encontrarían al amparo de la denominada 
Economía Social de Mercado y bajo el resguardo de un Estado regulador, cuyo rol no podía minimizarse.

Estas interrelaciones entre un Estado Social y Democrático de Derecho, aunado a un régimen económico de Economía Social de Mercado ponen de manifiesto que "la economía no constituye un fin en sí mismo, sino que es un instrumento al servicio de la persona humana y de su dignidad". En tal sentido el poder económico tiene que ser limitado por la Constitución, a fin de evitar que dicho poder degenere en un abuso del mismo ${ }^{1}$.

En este contexto cabe preguntarse ¿Cuáles son los lineamientos que debe seguir el Estado en su actividad reguladora? La respuesta a esta interrogante es la finalidad esencial de este análisis.

\section{LOS SISTEMAS ECONÓMICOS TRADICIONALES}

A lo largo de los años se ha demostrado cómo los constituyentes en las democracias pluralistas se concentran constantemente sobre temas del mercado y de Economía Social de Mercado $^{2}$.

Tradicionalmente la historia económica mundial refleja que los diferentes sistemas económicos se encuentran regidos por postulados ideológicos transportados desde épocas antiguas. ${ }^{3}$ De los diferentes modelos de vida económica, dos son los modelos de economía que han configurado los distintos regímenes de la sociedad mercante. Por un lado se hallan sistemas orientados por una economía de libre mercado; y por otro, sistemas donde la economía planificada es la base de su desarrollo. El hecho que una sociedad se organice según uno u otro modelo no es más que fruto de su historia ${ }^{4}$.

\footnotetext{
${ }^{1}$ Cfr. LANDA ARROYO, César. "Principios rectores y derechos fundamentales del administrado en el marco de la Constitución Económica de 1993", Revista de Jurisprudencia y Doctrina: Constitución Económica del Perú - Foro Económico Asia - Pacífico [APEC]. Nº 06, Año III, 2008, p. 53.

${ }^{2}$ Cfr. HABERLE, Peter. "Siete tesis para una teoría constitucional del Mercado", Revista de Derecho Constitucional Europeo [ReDCE], No 5, Junio 2006, pp. 11-30, p. 41. [Traducido por Miguel Azpitarte Sánchez].

${ }^{3}$ Un sistema económico es la organización que surge a partir de las relaciones entre los agentes que operan en una sociedad. VER en ARBÓS, Eulàlia [Editor]. Atlas de Economía: El comercio en la era global, España, Parramón Ediciones, 2010, pp. 38-49

${ }^{4}$ Ibídem.
} 
Por un lado, aquellos sistemas que operan en el marco de una Economía de Libre Mercado consideran que los agentes de éste son quienes se auto regulan - sean productores y/o consumidores -dado que el mercado interactúa de manera independiente y se vale, únicamente, de las fuerzas de la oferta y la demanda. Dicha auto-regulación tiene como principal fundamento la obtención de un fin inmediato, traducido en la búsqueda del interés individual, y de un fin último reflejado en el beneficio colectivo de la sociedad.

Para explicar estos planteamientos ADAM SMITH, teórico y defensor de este modelo, afirma que las ventajas que genera la aplicación de estos postulados son suficiente justificación para aceptarlos. El autor citado señala: "No es por la benevolencia del carnicero, del cervecero y del panadero que podemos contar con nuestra cena, sino por su propio interés". Todas estas afirmaciones se refuerzan con un concepto absoluto de libertad.

De esta manera quienes defienden la economía de libre mercado plantean que la unión del interés del mercado y la competencia empresarial permiten una asignación óptima de recursos y la fijación de precios de forma automática, por lo que la intervención del Estado es innecesaria. ${ }^{5}$ Adam Smith creía conveniente que mejor era dejar hacer a los mercados y que ellos se autoregulasen, ${ }^{6}$ de modo que concebían la libertad de mercado como la clave para el funcionamiento óptimo de la sociedad en general, por lo que los temas de intervención del Estado serían limitados. ${ }^{7}$

Por otro lado, existen sistemas donde la regulación de la vida económica se deja en manos del Estado, por lo que las posturas liberales anteriormente explicadas carecen de todo fundamento. Este modelo económico se conoce con el nombre de Economía Planificada.

En virtud de este estándar se considera que el Estado, al ser el propietario de los medios de producción y de todos los bienes en general, es también propietario de las empresas, y por lo tanto es él quien dirige directamente su actividad económica, relegando las fuerzas operativas de sus mismos agentes. Es decir, a través de este modelo se admite la existencia de un Estado centralizado dedicado a elaborar directivas económicas que deciden qué se debe producir, cómo se debe

\footnotetext{
${ }^{5}$ Esto también se conoce como liberalismo económico. VER en ARBÓS, Eulàlia. [Editor]. Op. Cit. p. 49

${ }^{6}$ De esta concepción surge la tradicional frase: "Dejar hacer dejar pasar".

7 Por ejemplo se debe intervenir en temas de seguridad, construcción de infraestructura, para asegurar el cumplimiento de las reglas de competencia por parte de las empresas, entre otros.
} 
producir, a quién va dirigida dicha producción y cuál debe ser el precio de venta de todos los productos 8 .

A la inversa de lo que sucede en el modelo de la economía de libre mercado, en la economía planificada el Estado juega un rol preponderante y es quien, a través de su intervención, debe indicar cuál es la mejor propuesta para su desarrollo. El fundamento de sus postulados radica en su objetivo final, el logro de un mínimo nivel de bienestar de todos los ciudadanos 9 .

Bajo ambos escenarios, las diferentes economías a nivel mundial han adoptado fórmulas intermedias, habiéndose llegado a configurar modelos con características propias de cada sistema.

Una de estas variaciones aparece con el surgimiento de las economías mixtas, en virtud de las cuales el Estado puede intervenir económicamente, al tiempo que colabora con la iniciativa privada, orientando su actividad, pero de manera genérica; diseñando Políticas de Estado que fomenten un desarrollo equilibrado con las economías globalizadas, conservando así la aplicabilidad de la Ley Económica de oferta y demanda.

Este contexto configura un modelo ajustado a las necesidades, tanto del Estado como de los demás agentes del mercado. En razón de este nuevo marco económico se consideraba que allí donde el mercado falla, el papel del Estado se hace indispensable. Una conclusión simple permitió fortalecer sus fundamentos: La acción conjunta del modelo privado y el público garantizan el desarrollo económico ${ }^{10}$.

\section{SURGIMIENTO DE UN NUEVO MODELO ECONÓMICO: ECONOMÍA SOCIAL DE MERCADO}

Los fracasos de la aplicación de los lineamientos del liberalismo económico y de los que corresponden a una economía planificada no tardaron en aparecer. Uno y otro modelo reflejaban conductas extremas que sólo tenían efectos negativos para la sociedad. Entre las consecuencias de sus erróneas concepciones de la economía aparecieron desequilibrados crecimientos económicos,

\footnotetext{
${ }^{8}$ Cfr. ARBÓS, Eulàlia [Editor]. Op. Cit.. p. 49.

${ }^{9}$ Un modelo económico de esta naturaleza es criticado porque nada justifica entender la necesidad del Estado para controlar todos los aspectos de la economía de un país, creando un gran aparato burocrático que, a menudo, se vuelve ineficiente.

${ }^{10}$ Cfr. ARBÓS, Eulàlia [Editor]. Op. Cit., p. 49.
} 
concentraciones excesivas de poder, profundización de desigualdades sociales, agudización de exclusión social, burocracia, y hasta se crean sistemas públicos ineficientes.

Desde ambas perspectivas el concepto "libertad" fue mal entendido y no llevó más que a desconocer la concepción real del hombre y de la sociedad, entendiéndose que el Estado era inerte ante la actividad económica o que tenía una suerte de súper poderes que le permitían actuar con total arbitrariedad.

Debido a las deficiencias de ambos regímenes económicos se plantea la necesidad de formar un modelo que facilite la interacción de los mercados, pero al mismo tiempo intervenga cuando dicha actuación presente dificultades. GALLEGOS MOLINA muy acertadamente señalaba:

“[...] Es función del Estado compatibilizar el interés privado con el interés social; que tenga a la justicia como valor rector, en equilibrio dinámico con la libertad, fundamentando en ambos la construcción de una sociedad con mayores niveles de equidad. El mercado [...] es el más eficiente asignador de recursos, pero para que ello sea así debe funcionar de tal forma que permita, la concurrencia libre y competitiva de los agentes económicos. Ello implica organizar el mercado y la competencia, pues no son leyes naturales las que gobiernan o determinan su operatividad. Sólo así los beneficios alcanzarán a la mayoría y podrá limitar los factores de poder económico local y mundial $[\ldots]^{11,}$

De esta forma, surge una nueva propuesta denominada Economía Social de Mercado, cuyos antecedentes más próximos se remontan a la época de Alemania de la post guerra de los años de 1945 y $1948^{12}$, fecha a partir de la cual el mismo gobierno alemán, tras evaluar los avances científicos que diversos estudios habían logrado sobre el tema, los implementa, direccionándolos a los ámbitos de la economía, de la política y de la sociedad, logrando definir un modelo económico social que tendría como base la combinación de la competencia funcional y la seguridad social. ${ }^{13}$

\footnotetext{
${ }^{11}$ GALLEGOS MOLINA, Luis. Economía Social de Mercado, Medio Ambiente y Responsabilidad Social Empresarial, Lima, Impresiones de Tarea Asociación Gráfica Educativa, 2008, pp. 12-13.

${ }^{12}$ Cfr. RIVADENEIRA FRISCH, Juan. Economía Social de Mercado, Quito, Ediciones de la Fundación Konrad Adenauer, 2009, pp. 7-9.; y además se precisa: "Este modelo fue llevado a cabo gracias a los estudios de Alfred Müllen - Armack, en especial en su obra "Dirección Económica y Economía de Mercado" publicada en 1976. Los primeros defensores de la Economía Social de Mercado fueron, además de Müllen Armack, los integrantes de la Escuela de Friburgo, en especial: Walter Eucken, Leonhard Miksch, Franz Böhm, Wilhelm Röpke y Alexander Rüstow.

${ }^{13}$ En este contexto, en junio de 1948 Ludwig Erhard implementa la Reforma Económica, para que tiempo después se produzca la creación oficial de la República Federal Alemana. VER en BODO, Herzog. "60 años
} 
La Economía Social de Mercado es un modelo que surge como un intermedio entre el liberalismo económico y la economía dirigida. Es decir, entre los liberales, que sostenían que la economía sería exitosa en la medida en que el Estado tenga una participación eficiente y fuerte pero reducida a temas que se enfoquen en desarrollar las actividades de actores privados con libertad; y los socialistas, quienes enfocaban al Estado como el actor central y protagonista en la economía ${ }^{14}$.

ALFRED MULLER-ARMACK, uno de sus principales exponentes, señala que se trata de un "sistema que combina la competencia sobre la base de la iniciativa libre de los individuos con la seguridad social y el progreso social ${ }^{15}$ ". Es decir, se trata de una economía de mercado controlada socialmente. Completando la idea, algunos autores ${ }^{16}$ señalan que esta propuesta no presupone ni la centralización de la actividad económica, ni la total desregulación del mercado sin ningún tipo de redistribución de las ganancias, sino una combinación que equilibre ambas situaciones.

Para destacar el carácter reconciliador de la Economía Social de Mercado MÜLLERARMACK caracteriza sustancialmente el concepto y lo califica como una "eirénica social" [del

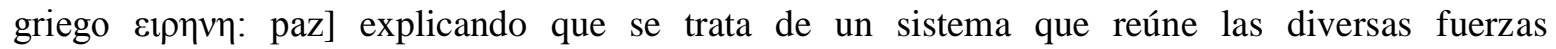
individuales y sociales de un país para fomentar la estabilidad y satisfacción en lo social y en lo económico. La libertad económica personal como objetivo y valor debería estar equilibrada por otros valores, como la solidaridad y la justicia social.

Desde sus inicios, la ECONOMÍA SOCIAL DE MERCADO se ha configurado a través de cinco pilares: Fomento de la Iniciativa privada, protección de la propiedad, defensa de la Competencia, implementación de sistemas de responsabilidad individual y reconocimiento de libertades económicas $^{17}$. Todos ellos orientados a la búsqueda de correcto funcionamiento de los mercados, de la vida económica social y del bien común.

Sin embargo, desde una perspectiva más específica, RIVADENEIRA FRISCH, agregando un nivel de análisis, explica que la teoría sobre la Economía Social de Mercado distingue dos

de Economía Social de Mercado: pasado, presente y futuro", Serie de $N^{o} 01$ de Economía Social de Mercado, № 01, Vol. 01, Fundación Konrad Adenauer, Guatemala, 2009, pp. 9-14.

${ }^{14}$ Este es el modelo de la Economía centralizada o planificada.

${ }^{15}$ MÜLLER- ARMACK, Alfred. "Economía Social de Mercado", Economía Social de Mercado: un proyecto económico y político alternativo. Buenos Aires, Ciedla, 1983, p. 25.

${ }^{16}$ Cfr. SILVA PENEDA, José A. "La Economía Social de Mercado en la Unión Europea”, Serie de $N^{o} 01$ de Economía Social de Mercado, N 01, Vol. 01, Fundación Konrad Adenauer, Guatemala, 2009, pp. 31-43.

${ }^{17}$ RIVADENEIRA FRISCH, Juan. Op. Cit., p. 9-10. 
esferas $^{18}$. Por un lado se encuentran los principios generales; y por otro, los principios operacionales; ambos vinculados al compromiso social de su adecuado desenvolvimiento ${ }^{19}$.

En el siguiente esquema se puede apreciar con claridad tales conceptos, a saber:

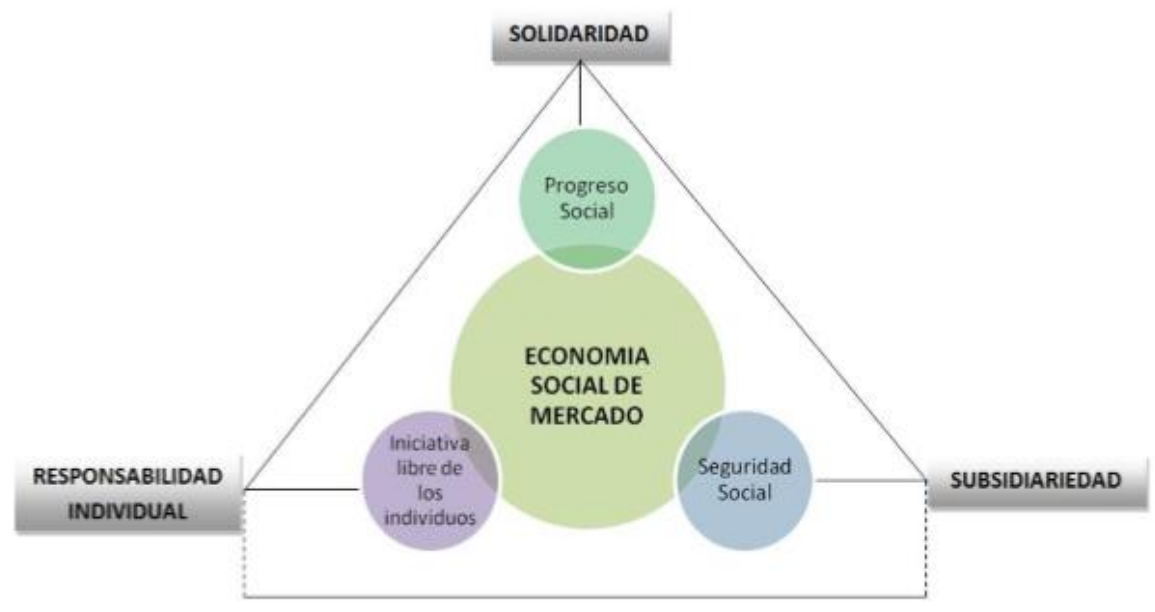

Según esta doctrina existen tres principios generales y tres principios operacionales. Los primeros son postulados cuya aplicación responde a las necesidades de la vida en sociedad en general, y los segundos son aquellos, que atendiendo a su finalidad económica, permiten trasladar el desarrollo de los principios generales al desarrollo de la economía.

Entre los principios generales se identifica:

Responsabilidad individual: relacionada directamente con el rendimiento de cada uno de los individuos que componen la sociedad.

Solidaridad: alejada del concepto de caridad, y referida al aporte que en sus diferentes dimensiones realizan los distintos actores para el desarrollo social.

\footnotetext{
${ }^{18} \mathrm{Cfr}$. Ibídem.

${ }^{19}$ También se ha referido a estos principios para justificar algunos de los objetivos estatales [regulador] al señalar: que "Los principios rectores del orden económico que la Constitución consagra [Economía Social de Mercado] orientan la labor de la Administración Pública en relación a la economía y resultan relevantes, entre otras razones, porque las decisiones constitucionales fundamentales son, al tiempo, los valores básicos del Derecho Administrativo". VER en SHIMIDT-ASSMANN, Eberhard. La teoría general del Derecho Administrativo como sistema Instituto Nacional de Administración Pública. Madrid, Marcial Pons, 2003, p.
} 51. 


\section{IUS}

Subsidiariedad: considerada una herramienta de corrección de las inequidades y procura de la justicia social.

Y entre los denominados principios operacionales distingue:

Reconocimiento de la Propiedad privada, asegurada por los instrumentos constitucionales y legales necesarios y efectivos.

Libertad de competencia: para velar por el normal funcionamiento del mercado.

-

Responsabilidad individual: requerida al momento de fijar roles y compromisos que desempeñan los distintos actores.

-

Precios definidos por el mercado: con libre interacción de la oferta y la demanda, respuesta de aquella "mano invisible" definida por Adam Smith y entendida como un mecanismo aunque no perfecto, ventajoso, debido a la facilidad para control de prácticas desleales como monopolios y oligopolios.

Información imperfecta: característica al momento en que el consumidor o el productor desea interactuar en la economía, lo que hace imprescindibles amplios esfuerzos para que la misma llegue a los distintos actores.

-

Precio del trabajo: relacionado principalmente con la política salarial y que reconoce la importancia del consenso entre Estado, empleadores y trabajadores [agrupados en sindicatos].

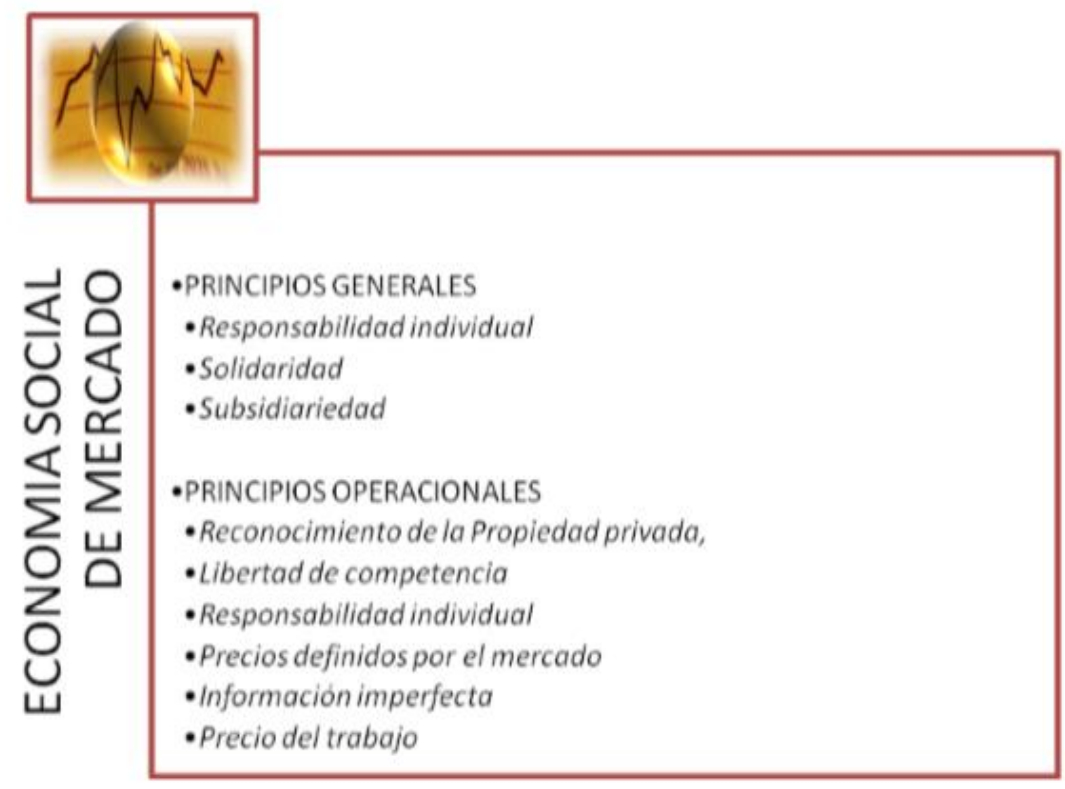


Hoy el Perú, goza de un reconocimiento constitucional de la Economía Social de Mercado, el cual antecede desde la vigencia de la Carta Constitucional de 1979, derogada por el Texto Constitucional de 1993, aún vigente y que admite tales reconocimientos.

\section{RÉGIMEN ECONÓMICO PERUANO SEGÚN LA CONSTITUCIÓN POLÍTICA DEL PERÚ DE 1993}

A nivel constitucional, nuestra Carta Magna reconoce que el Perú se rige bajo una Economía Social de Mercado. Este reconocimiento antecede desde 1979.

No obstante, el primer antecedente de la relevancia jurídica de algunos temas económicos se remonta hacia 1823, época en la que constitucionalmente, se realza la función de la Hacienda Pública, cuya labor se orientaba a la captación de rentas y demás productos correspondientes al Estado $^{20}$. En 1828, el tema vuelve a tomar vigencia al realzar la actividad económica del Estado a través del manejo presupuestario en el interior del sistema público.

Desde aquella época el pensamiento económico de los sucesores constituyentes ha ido explayándose, hasta que en 1979 el Preámbulo de la misma Constitución reconoce, aunque de forma muy general, que las actividades económicas de la sociedad se ejercen según los lineamientos de una Economía Social de Mercado.

Recién en la década de los noventa, con la dación de la actual Carta Constitucional se realizan algunas modificaciones de fondo ${ }^{21}$.

\subsection{Marco normativo constitucionalmente reconocido}

En razón de los cambios económicos generados por la globalización, el constituyente del 93' creyó conveniente que la legislación tenga por objeto esencial definir "reglas de juego"

\footnotetext{
${ }^{20}$ Cfr. MONTOYA CHÁVEZ, Víctor Hugo. "La configuración jurisprudencial del constitucionalismo económico", Revista de Jurisprudencia y Doctrina: Constitución Económica del Perú - Foro Económico Asia-Pacífico APEC]. Año III, No 06, 2008, p. 71.

${ }^{21}$ Mientras que la antigua Carta se mantenía al margen de las connotaciones ideológicas y se concentraba en dejar enunciadas las orientaciones pertinentes a la consecución del desarrollo nacional y el estado de bienestar; la actual Constitución opta resueltamente por disposiciones en las que el perfil ideológico de neoliberalismo resulta visible. VER en BERNALES BALLESTEROS, Enrique. La Constitución de 1993. Comentarios, $5^{\circ}$ Edición, Lima, Editora RAO SRL, 1999, p. 347.
} 
objetivas para los procesos económicos que garanticen la libertad, y que a la vez sean reflejo de valores democráticos y eficientes, en la cual el rol regulador del Estado no puede minimizarse. ${ }^{22}$

En la Constitución vigente, el Título III regula el modelo de economía que tiene el país, y lo hace bajo la denominación de "Del Régimen Económico". Este título se encuentra dividido en cinco capítulos en los que de forma concreta se consagran las diversas manifestaciones de la vida económica peruana. El Capítulo I referente a los Principios Generales ${ }^{23}$ define los lineamientos característicos y principios generales, los cuales serán aplicados posteriormente en cada área específica. Por su parte, también forma parte integrante de este marco el Capítulo II con el título 'Del ambiente y los recursos naturales ${ }^{24}$, el Capítulo III que se refiere a la Propiedad ${ }^{25}$, el Capítulo IV que trata el Régimen Tributario y Presupuestal ${ }^{26}$, el Capítulo V referido a la Moneda y la Banca $^{27}$ y por último el Capítulo VI que consagra el Régimen Agrario y de las Comunidades Campesinas y Nativas ${ }^{28}$; siendo toda esta estructura un claro reflejo de los pilares de la Economía Social de Mercado, los cuales fueron estudiados anteriormente.

Dentro de esta red jurídica, el tema que interesa a la presente investigación se encuentra en el Capítulo I, concretamente en el artículo $58^{\circ}$ en el cual, luego de identificar el modelo de Economía Social de Mercado, precisa que si bien la iniciativa privada es libre ${ }^{29}$, ella no puede ser ejercida en contraposición con el interés general y social. Literalmente, el artículo en referencia señala: "La iniciativa privada es libre. Se ejerce en una Economía Social de Mercado. Bajo este régimen, el Estado orienta el desarrollo del país, y actúa principalmente en las áreas de promoción de empleo, salud, educación, seguridad, servicios públicos e infraestructura."

\footnotetext{
${ }^{22}$ César Landa justifica este objetivo al señalar que "la economía no constituye un fin en sí mismo, sino que es un instrumento al servicio de la persona humana y de su dignidad", por lo que el poder económico tiene que ser limitado por la Constitución, dado que de esa forma se evitará que dicho poder degenere en un abuso del mismo; esto es lo que configura las interrelaciones entre un Estado Social y Democrático de Derecho que tiene un régimen económico de Economía Social de Mercado. VER en LANDA ARROYO, César. Op. Cit. p.

${ }^{23}$ Art. $58^{\circ}$ al Art. $65^{\circ}$ de la C.P.P. 1993.

${ }^{24}$ Art. $66^{\circ}$ al Art. $69^{\circ}$ de la C.P.P. 1993.

${ }^{25} \mathrm{Art} .70^{\circ}$ al Art. $73^{\circ}$ de la C.P.P. 1993.

${ }^{26}$ Art. $74^{\circ}$ al Art. $82^{\circ}$ de la C.P.P. 1993.

${ }^{27}$ Art. $83^{\circ}$ al Art. $87^{\circ}$ de la C.P.P. 1993.

${ }^{28}$ Art. $88^{\circ}$ al Art. $89^{\circ}$ de la C.P.P. 1993.

${ }^{29} \mathrm{El}$ Estado reconoce a favor del individuo una serie de libertades económicas.
} 50. 
Hace algunos años el Tribunal Constitucional peruano ${ }^{30}$ no ha resultado ajeno al tema. Desde su jurisprudencia, y refiriéndose al concepto de Economía Social de Mercado, ha señalado que:

“esta noción se refiere a un tipo de organización económica regulado por un régimen jurídico de descentralización e independencia frente al Estado, el cual está destinado a asegurar la existencia de una pluralidad de agentes económicos en lo relativo a la libre iniciativa para participar en la actividad económica y la libre competencia, para ofertar y demandar la provisión y suministro de bienes y servicios al público en general. [...] El objetivo último no es el siempre libre intercambio de bienes y servicios, sino el aseguramiento de la calidad de vida de la población y la transformación de la productividad individual en progreso social para todos ${ }^{, 31}$.

En tal sentido se interpreta que en un modelo de Economía Social de Mercado, tanto los particulares como el Estado asumen deberes específicos, todos orientados al progreso social y al desarrollo de la población. Esto significa que si bien, por una parte a los particulares se les reconoce derechos y libertades económicas, éstas deben ser asumidas con responsabilidad en beneficio de la sociedad.

Tal como lo ha señalado la jurisprudencia, la Economía Social de Mercado determina que el Estado no sea indiferente a las actividades económicas, sin embargo, dicha intervención no debe importar arbitrariedad. De esta forma el Estado asume una función supervisora y reguladora, cumpliendo al máximo su obligación de vigilar, garantizar y corregir las deficiencias que la realidad le presente.

En consecuencia, tal como lo manifiesta CESAR LANDA ARROYO, nos encontramos frente a un modelo económico que reconoce libertades y que está al servicio de la persona, en el que el mercado no es la medida de todas las cosas, dado que no es la medida del ser humano ${ }^{32}$. Este reconocimiento se presenta como una condición sine qua non del Estado Social Democrático

\footnotetext{
${ }^{30}$ En adelante TC.

${ }^{31}$ STC del 26 de abril de 2004. Expediente No 018 - 2003 - AI / TC. [Jorge Power Manchego-Muñoz, en representación de más de cinco mil ciudadanos contra el Congreso de la República. Solicita la declaratoria de inconstitucionalidad del artículo $1^{\circ}$ de la Ley $\mathrm{N} .^{\circ}$ 27633, modificatoria de la Ley $\mathrm{N} .^{\circ} 27143$, Ley de Promoción Temporal del Desarrollo Productivo Nacional.]

${ }^{32}$ LANDA, César. Op. Cit. p. 53
} 
de Derecho, compatible con los fundamentos axiológicos y teleológicos inspiradores del Estado, y sin el cual éste no puede existir. ${ }^{33}$

Llegados hasta aquí, ahora conviene analizar cuáles son los derechos y libertades que un modelo económico de esta naturaleza plantea, a fin de analizar el rol que le compete al Estado en las esferas de la economía, su forma de intervención, de regulación y de otros aspectos relacionados con la administración de la economía política.

\subsection{Pilares de la Economía Social de Mercado en la CPP de 1993}

Sobre este tema GIMENO FELIÚ ha señalado que los principios constitucionales que informan al "modelo económico peruano, o llamado también marco jurídico de la economía son: Reconocimiento del Estado peruano como un Estado social y democrático de derecho, reconocimiento de la dignidad de la persona humana, la Igualdad, la Economía Social de Mercado, la Libre iniciativa privada, la actuación subsidiaria del Estado en la economía, e 1 reconocimiento de libertades patrimoniales que garantizan el régimen económico tales como: el derecho a la propiedad, el derecho a la libre contratación, la libertad de trabajo, la libertad de empresa, la libertad de comercio y la libertad de industria., regulación de los derechos de los consumidores y los usuarios, presencia de un Estado vigilante, garantista y corrector, presencia y autonomía de organismos reguladores. Todos, integrantes de una red soporte y responsable del desarrollo de la Economía de un país"34.

Sin embargo, de acuerdo a lo planteado por nuestra Norma Constitucional la Economía Social de Mercado recogida en el Art. $51^{\circ}$ de la Constitución del 19...., se fundamenta en tres principios esenciales: el reconocimiento de la autonomía privada, el reconocimiento de las libertades económicas y la aceptación del principio de subsidiariedad ${ }^{35}$. Por ende adquiere especial

\footnotetext{
${ }^{33}$ No obstante, aun cuando la técnica legislativa en materia económica ha pretendido ser lo más clara posible, parece necesario reprocharle cierto orden a la sistematización.

${ }^{34}$ GIMENO FELIÚ, José María. "Sistema Económico y Derecho a la libertad de empresa versus reserva al sector público de actividades económicas", Revista de Administración Pública, № 135, Madrid, 1994, pp. 194-212.

${ }^{35}$ No obstante de esta afirmación, otros autores afirman que constitucionalmente un país no se puede adherir a través de su Constitución a un determinado sistema económico; pues esto se traduciría en una materialización de la ideología política-económica. En España, por ejemplo, su texto constitucional no hace ninguna declaración expresa del sistema económico constitucional, sin embargo este se perfila unas líneas maestras que se entresacan como consecuencia de una interpretación conjunta de los derechos fundamentales que se atribuyen a los agentes económicos, de los principios en que la actividad económica debe inspirarse y de los títulos de intervención reconocidos por el Estado. VER en VARDÚ, Pablo Lucas. "Los títulos Preliminar y
} 
relevancia los principios, derechos y libertades económicas que el Estado reconoce a favor de sus miembros; pero al mismo tiempo, también importa que dicho reconocimiento se compatibilice con el rol y las funciones que tiene el Estado en torno a su participación en el mercado, debiéndose diferenciar su actuar como empresario y su actuar como regulador. Analicemos.

El primer eje del Sistema jurídico nacional, y de muchos sistemas jurídicos existentes es la Autonomía Privada, principio general del derecho de fuente constitucional ${ }^{36}$, reconocido tanto en la Carta de 1993 como en el Código Civil del 1984 ${ }^{37}$. Para FERNÁNDEZ SESSAREGO esta autonomía radica en la persona en cuanto ésta es un ser libertad y un ser autónomo, y es precisamente en esta libertad donde radica su autonomía, y que sustenta y fundamenta la "voluntad"38. Con tales consideraciones, el ordenamiento jurídico nacional, al reconocer la libertad intrínseca propia del ser y materializarlo en un dispositivo legal, pone de manifiesto que la esencia misma de nuestro sistema jurídico es el reconocimiento y respeto de la dignidad humana cuya máxima expresión son los postulados de la "Autonomía Privada"39/40.

En el mundo de lo económico esta cualidad de autodeterminación se refleja en la autonomía contractual $^{41}$, una de las principales manifestaciones del reconocimiento de la autonomía privada, y que han inundado el derecho privado tras su colonización en el derecho constitucional ${ }^{42}$.

Un segundo eje, que surge como consecuencia de nuestro modelo económico es el reconocimiento de determinadas Libertades. En sentido, nuestra actual Carta constitucional

Primero de la Constitución y la interpretación de los derechos y libertades fundamentales", Revista de la Facultad de Derecho de la Universidad Complutense № 02, Madrid, 1979, pp. 9-38.

${ }^{36}$ Cfr. HERAS ZÁRATE, Luis Henry. "La autonomía privada en las regulaciones de la Banca: transportando fundamentos filosóficos", La persona en el Derecho Peruano. Un análisis jurídico contemporáneo. EMEDECOSEGE, Lambayeque, 2010, pp. 293-309.

${ }^{37}$ Sus antecedentes inmediatos: C.C. de 1852 establecía en el Art. III - Título Preliminar que A nadie puede impedirse la acción que no está prohibida por la ley; y complementariamente en el artículo VII: "Ningún pacto exime de la observancia de la ley; sin embargo, es permitido renunciar a los derecho que ella concede siempre que san meramente privados y que no interesen al orden público". Así también en el Código de 1936 en el artículo $1328^{\circ}$ se señaló que "los contratos son obligatorios en cuanto se haya expresado en ellos [...] deben ejecutarse según las reglas de la buena fe y de la común intención".

${ }^{38}$ Cfr. FERNÁNDEZ SESSAREGO, Carlos. "El supuesto de la denominada 'autonomía de la voluntad",. En Contratación Contemporánea-Teoría general y principios. Lima - Bogotá: Palestra - Temis, 2000, p. 254 ${ }^{39}$ Cfr. TORRES VÁSQUEZ, Aníbal. Acto Jurídico, $2^{\circ}$ Edición, IBÍDEMSA, Lima, 2001, p. 121.

${ }^{40}$ Para confirmar dicha afirmación bastará con analizar el Art. $1^{\circ}$ de la Constitución el cual reconoce como fin supremo del Estado la protección de la persona humana y su dignidad.

${ }^{41}$ Constitución Política del Perú. Artículo $2^{\circ}$ inc. $14^{\circ}$.- Toda persona tiene derecho [...] A contratar con fines lícitos, siempre que no se contravengan leyes de orden público

${ }^{42}$ Cfr. HERAS ZÁRATE, Luis Henry. Op. Cit. pp. 293-309. 
reconoce la Libertad de empresa, Libertad de comercio, Libertad de industria, Libertad de contratar, Libertad de Iniciativa privada, entre otras.

El núcleo central de todas estas libertades radica en la libertad de empresa, ${ }^{43}$ pero al mismo tiempo reposa en la libertad de competencia; la primera como garantía institucional del empresario, y la segunda como elemento protector del mercado. Las fuerzas sinérgicas de ambas libertades, terminan por delinearse expresamente en el principio de subsidiariedad, pilar esencial del modelo económico.

\section{ECONOMÍA SOCIAL DE MERCADO}
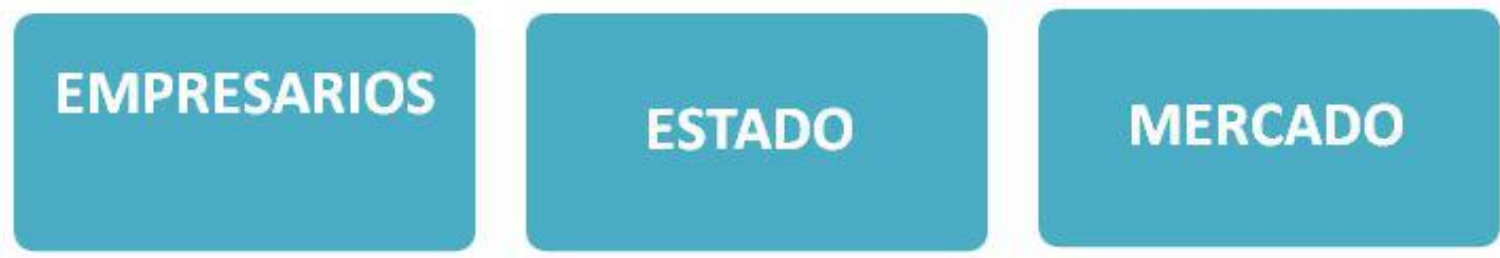

Libertad de Empresa
Principio de Subsidiariedad

\section{Libre}

Competencia

La libertad de empresa es entendida como la posibilidad de crear libremente personas jurídicas dedicadas a actividades lucrativas en las distintas formas que ellas asumen. ${ }^{44}$ Esta libertad se manifiesta como el derecho de las personas a elegir libremente la actividad ocupacional o profesional que desee o prefiera desempeñar, disfrutando de su rendimiento económico y satisfacción espiritual $^{45}$, pero con un marco de actuación auto determinativo que exige reconocer como fundamento y límite el modelo de la Economía Social de Mercado. En estos términos, tanto la

\footnotetext{
${ }^{43} \mathrm{Su}$ antecedente inmediato de regulación es la libertad de industria y de comercio que se reconocía en la Constitución de 1823.

${ }^{44}$ BERNALES BALLESTEROS, Enrique. Op. Cit., p. 354.

${ }^{45}$ Esta definición es conocida por el Tribunal Constitucional como la Teoría Subjetiva. STC del 11 de Julio del 2005. Expediente $\mathrm{N}^{\circ}$ 3330-2004-AA/TC. Recurso extraordinario interpuesto por don Ludesminio Loja Mori contra la Municipalidad Metropolitana de Lima, la Dirección Municipal de Comercialización y Defensa del Consumidor, y la Dirección de Fiscalización y Control de la Municipalidad Metropolitana de Lima.
} 
Constitución de 1979, como la Constitución de 1993 reconocen de manera expresa que la iniciativa privada y la libertad de empresa son derechos personales que reafirman el rol del Estado en tanto ente orientador del desarrollo del país ${ }^{46}$.

En este juego dual de libertades, la libertad de competencia, entendida como libertad conexa que opera de forma paralela a la libertad de empresa, es otro de los motores del sistema económico peruano actual.

$\mathrm{Su}$ reconocimiento constitucional radica en el Art. $61^{\circ}$ que reconoce el rol del Estado de facilitar y vigilar la libre competencia, y combatir las prácticas que la limiten. ${ }^{47} \mathrm{Su}$ finalidad es garantizar el correcto funcionamiento de la Economía Social de Mercado como sistema constitucionalmente adoptado ${ }^{48}$ y se diagrama como un freno y límite de descontroles, a la vez que se convierte en el orientador de las conductas de los agentes del mercado ${ }^{49}$.

La libertad de competencia forma parte del orden público económico y que al Estado le corresponde preservar, pues si el mercado se autorregulase acabaría en un caos en el cual las conductas anárquicas o las que sólo buscan el privilegio personal se impondrían. De esta manera la regulación no debe ser únicamente pro mercado, sino encausarse bajo el imperio de Estado de Derecho, lejos de la arbitrariedad y del subjetivismo, con aplicación de los principios de legalidad, responsabilidad administrativa y protección jurisdiccional de los derechos ${ }^{50}$.

Ahora bien, la interrelación entre ambas libertades ha sido puesta de manifiesto por el Tribunal Constitucional, el cual ha señalado: “un aspecto fundamental de la Economía Social de Mercado y una consecuencia principal de la libertad de acceso al mercado es la existencia de la

\footnotetext{
46 Al respecto, la segunda parte del artículo $59^{\circ}$ de la CPP del 93, refiriéndose al reconocimiento de las libertades económicas, expresa "El ejercicio de estas libertades no debe ser lesivo a la moral, ni a la salud, ni a la seguridad pública”.

${ }^{47}$ A nivel jurisprudencial el TC ha precisado que esta libertad, que se encuentra reconocido taxativamente en el ordenamiento, tiene dos aspectos esenciales: la libertad de acceso al mercado y la libertad de actuación en éste, reconociendo que es tarea del Derecho garantizar que se den las condiciones mínimas para que esta se manifieste. En este sentido se ha señalado que la libre competencia plantea el libre juego de la oferta y la demanda, y presupone la presencia de tres requisitos: 1] La autodeterminación de iniciativas o de acceso de agentes económicos al mercado. 2] La autodeterminación para elegir las circunstancias, modos y formas de ejecutar la actividad económica [calidad, modelo, volumen de producción, etc.] es decir la libertad de actuación dentro del mercado. 3] La igualdad de los competidores ante la ley [y la no discriminación]. STC del 26 de abril de 2004. Expediente Nº18 - 2003 - AI / TC.

${ }^{48}$ Cfr. KRESALJA, Baldo; OCHOA César. Derecho Constitucional Económico, Lima, Fondo Editorial de la Universidad Católica del Perú, 2009, p. 493.

${ }^{49}$ Ibídem, p. 220.

50 Cfr. OCHOA CARDICH, César. Jurisprudencia Constitucional Económica, Ediciones Caballero Bustamante, Lima, 2011, p. 219.
} 
libre competencia, sin la cual quedaría vacío el contenido del derecho a la libertad de empresa. Por ello el artículo $61^{\circ}$ de la Constitución delega al legislador la labor de garantizar el acceso al mercado en igualdad de condiciones, al tiempo de reprimir y limitar el abuso de posiciones de dominio o monopólicas a efectos de garantizar no sólo la participación de los agentes económicos, sino de proteger a quienes cierran el circulo económico en calidad de consumidores y usuarios ${ }^{51}$.

De esta forma tanto la libertad de competencia permite que la conducta de los empresarios y demás agentes del mercado sean vigiladas y preservadas por el Estado a fin crear mercados libres, competitivos y transparentes que logren la satisfacción de los intereses de los consumidores y usuarios en el funcionamiento eficiente de éstos. ${ }^{52}$ No obstante, dichas finalidades no puede entenderse plenamente, sin la interacción de un principio adicional, esto es el principio de subsidiariedad $^{53}$ en virtud del cual, el Estado sólo autorizado por ley expresa puede realizar actividad empresarial, directa o indirecta, por razón de alto interés público o de manifiesta conveniencia nacional ${ }^{54}$.

Este rol subsidiario del Estado se encuentra regulado en el artículo 60 de la CPP de 1993 en el cual, luego de reconocer la presencia de una economía pluralista, recoge el principio de subsidiariedad, haciendo referencia a la actuación del Estado en la actividad privada. Todo ello a fin de evitar desequilibrios del propio mercado, dado que el Estado al convertirse en agente de actuación económica tendría la ventaja de ser él mismo el que otorgue las leyes que más le favorecen, eliminando las posibilidades de competencia de los otros participantes. Más todavía, el artículo $61^{\circ}$ del mismo cuerpo legislativo recoge el deber del Estado de facilitar y vigilar la libre competencia, siendo una de sus exigencias combatir toda práctica que la limite, así como el abuso de posiciones dominantes o monopólicos.

${ }^{51}$ STC del 10 de agosto del 2009. Expediente $\mathrm{N}^{\circ}$ 03116-2009-PA/TC-LIMA. Cementos Lima contra Ministerio de Economía y Finanzas. Fundamento 3.2.

${ }^{52}$ Cfr. Ibídem.

${ }^{53}$ El principio de subsidiariedad se entiende desde dos perspectivas: una institucional y otra estatal. La primera impone el deber de no centralizar al más alto nivel aquellas decisiones que pueden ser adoptadas con igual o mayor eficiencia a un nivel político y administrativo inferior. Y la segunda pretende iluminar la actividad del Poder público, de modo que éste sea una ayuda para los grupos intermedios cuando se encuentren con obstáculos o incapacidades para regular por sí mismos sus intereses.

${ }^{54} \mathrm{El}$ Rol subsidiario del Estado está regulado en el artículo $60^{\circ}$ de la Constitución en el que se reconoce la participación en la actividad empresarial de forma subsidiaria y bajo expresa autorización legal, sea que se con ello se responda a situaciones de interés público o manifiesta conveniencia nacional. VER en KRESALJA, Baldo; OCHOA César. Op. Cit., p. 358. 
Entonces, queda claro que lo que hace la Carta Constitucional de 1993 es recoger el rol subsidiario del Estado como empresario, pero no un rol subsidiario como regulador. ${ }^{55}$

Con lo antes explicado es por demás evidente que el reconocimiento constitucional de las libertades económicas no limita, en lo absoluto, el rol regulador del Estado siempre que esto no implique arbitrariedad legislativa. Es en este ámbito donde los organismo reguladores desempeñan una obligación especial quienes al asumir la misión asignada en sus respectivos sectores, deben generar una verdadera competencia entre los distintos agentes económicos y cuyo beneficio finalmente recaerá en los usuarios.

A todo ello, el máximo intérprete constitucional ha agregado algunas características que van a permitir optimizar la función que le asiste en una Economía Social de Mercado. Con estos términos queda claro que al Estado le corresponde una función orientadora, la misma que ha sido caracterizada por el Tribunal al señalar que:

El Estado puede formular indicaciones, siempre que estas guarden directa relación con la promoción del desarrollo del país;

Los agentes económicos tienen la plena y absoluta libertad para escoger las vías y los medios a través de los cuales se pueden alcanzar los fines planteados por el Estado; y,

El Estado debe estimular y promover la actuación de los agentes económicos ${ }^{56}$.

\section{FACULTADES DEL ESTADO EN REGULACIÓN ECONÓMICA}

Luego de apreciar la estructura legislativa que la Constitución vigente ha elegido para regular las bases de su modelo económico, es fácil percibir algunos alejamientos de la actual constitución respecto de un modelo económico de tipo intervencionista, sin llegar a establecer

\footnotetext{
${ }^{55}$ Sin embargo, el criterio de interpretación del TC se ha extendido a un nivel adicional al señalar que la intervención subsidiaria del Estado corresponde cuando aquellos responsables de servir al público se han olvidado que la legitimidad del beneficio individual que les concede determinada actividad empresarial debe ser correlativa con los intereses de la sociedad. Concretamente, en el EXP. $\mathrm{N}^{\circ}$ 0008-2003-AI/TC el Tribunal ha precisado: "La premisa de que la mejor regulación de la economía es la 'no regulación', es una falacia [...]. Es por ello que al Estado le compete supervisar el correcto desenvolvimiento de la economía, previo convencimiento de la función social que ella cumple en la sociedad. Por tal razón, tendrá como deber intervenir en aquellas circunstancias en que los encargados de servir al público hubiesen olvidado que el beneficio individual que les depara la posesión y explotación de un medio de producción o de una empresa de servicio, pierde legitimidad si no se condice con la calidad y el costo razonable de lo ofertado. En buena cuenta, es menester enfatizar que la satisfacción de las necesidades del consumidor y del usuario es el punto de referencia que debe tenerse en cuenta al momento de determinar el desenvolvimiento eficiente del mercado". Cfr. Ibídem. Fundamento $\mathrm{N}^{\circ} 42$.

${ }^{56}$ Ibídem, fundamento $\mathrm{N}^{\circ} 39$.
} 
principios claros respecto al rol que el Estado le toca desempeñar en la Economía, incurriendo en indebidas referencias o en causas de otros problemas 57 .

Por ello, paralelamente a los principios de libertades económicas, la Carta Constitucional también consagra algunas funciones que le competen al Estado en su calidad de ente superior, y estas son: 1] Facilitar y vigilar la libre competencia. 2] Garantizar la libre tenencia y disposición de moneda extranjera. 3] Defender el interés de los consumidores y usuarios. 4] Velar por la salud y seguridad en la población. 5] Promocionar pequeñas empresas. 6] Reconocer pluralismo económico.

Lo ideal es la creación de un Estado garante del funcionamiento del mercado. Sin embargo, ¿Cuál es el verdadero alcance y los límites de esta actividad estatal?

La forma como interviene el Estado en una sociedad ha variado a lo largo de los años, y así lo han demostrado las configuraciones de los diferentes sistemas económicos estudiados en la primera parte de este análisis.

Un Estado dirige su actuar a través de la configuración de las políticas públicas, las cuales constituyen los lineamientos que dirigen y estructuran el régimen de cada gobierno. El nivel de intervención del Estado en la vida social de su población, variará de acuerdo a las ideologías propias del gobernante de turno, y por tanto las consecuencias de una y otra época serán distintas. Un claro ejemplo lo muestra JOACHIM WIEMEYER cuando señala: "En tanto que los países en desarrollo padecen el hecho de que el Estado cumple de manera muy imperfecta sus funciones básicas [Estado de derecho, infraestructura, educación, seguridad social], existen otros en los que el Estado despliega una actividad tan voluminosa que asfixia cualquier actividad económica privada [Corea del Norte, Cuba, el bloque soviético en su momento ${ }^{58}$ ]".

57 Cfr. GUZMAN NAPURÍ, Christian. Introducción al Derecho Público Económico. Lima, Ediciones Caballero Bustamante, 2009, p. 23.

${ }^{58}$ WIEMEYER, Joachim. “Crisis del Sistema Financiero: ¿Crisis de la Economía Social de Mercado?”, Serie de Economía Social de Mercado, No 02 Vol. 01, Fundación Konrad Adenauer, Guatemala, 2009, pp. 25-43. Ver también DOMINIK H. Ernste. "Una perspectiva ordoliberal de la Economía Social de Mercado. Basado en los "Principios de política económica" de Walter Eucken [Traducción], Serie de Economía Social de Mercado, No 02 Vol. 01, Fundación Konrad Adenauer, Guatemala, 2009, pp. 45-59: "El colapso de la Unión Soviética y del ex bloque comunista demostró ante los ojos de todo el mundo que las instancias centrales de un gobierno no están en condiciones de planificar y controlar la economía de modo tal que mejore el bienestar social de todo el pueblo". 
Entonces, a fin de analizar el concepto de Economía Social de Mercado en el marco de nuestro análisis es preciso preguntarse ¿Cuáles son los lineamientos que debe seguir el Estado en su actividad reguladora?

JOACHIM WIEMEYER, responde parcial y genéricamente esta interrogante resaltando tres elementos del modelo económico, los cuales son:

1. Estableciendo condiciones que permiten desarrollar una actividad económica [orden jurídico, seguridad interior y exterior, infraestructura, educación, agricultura, minería entre otros]

2. Adecuado funcionamiento de los mercados [competencia, política ambiental, estabilidad de la moneda]

3. Corrigiendo los resultados obtenidos en el mercado ante crisis coyunturales, estructurales, distribución de ingresos, etc.

La Economía Social de Mercado exige como presupuesto la existencia de una sinergia adoptada por el reconocimiento de las libertades económicas, pero al mismo tiempo por la aceptación de un Estado orientador del desarrollo económico. Es decir, el Estado tendrá la misión de intervenir en casos de concentraciones del poder económico, haciendo indispensable evitar la formación de monopolios y trusts y más aún que se incurra en un abuso de poder por parte de monopolios naturales [electricidad, gas, etc.].

De forma complementaria, a nivel jurisprudencial, el TC en el Expediente $\mathrm{N}^{\circ}$ 018-2003AI/TC ha señalado que también es FUNCIÓN DEL ESTADO EN MATERIA ECONÓMICA $\underline{\text { asegurar las libertades económicas }}^{59}$; señalando en este sentido que ante la concurrencia e intercambio auto-determinativo, en donde aparecen de un lado los ofertantes de bienes y servicios y, de otro, los consumidores o usuarios, el Estado tiene la obligación de reconocer y efectivizar un conjunto de garantías destinadas a asegurar el goce de las libertades económicas, los derechos laborales y el derecho a la propiedad de los agentes económicos ${ }^{60}$.

Sin embargo, bajo este contexto, no debemos olvidar que a través de la regulación económica los poderes públicos que intervienen en un sector determinado de la economía, afectando el funcionamiento de los mercado, no debe generar arbitrariedad. La regulación económica, indica BREYER, es el instrumento en manos de los poderes públicos a través del que

${ }^{59}$ Cfr. STC del 26 de abril de 2004. Expediente $N^{\circ} 018-2003$ - AI / TC. Fundamento No 2. Esto es la libertad de empresa, libertad de contratar, la libertad de inversión, entre otros.

${ }^{60} \mathrm{Cfr}$. Ibídem. 
intentan controlar los precios, la producción, la entrada y salida del mercado, las condiciones de la producción de bienes o prestación de servicio, las decisiones de la calidad de los productos de las empresas y evitar que las decisiones privadas puedan lesionar el interés público ${ }^{61}$. Por consiguiente, y siguiendo a LOPEZ DE CASTRO GARCÍA MORATO \& ARIÑO ORTÍZ, la regulación es la actividad normativa en la que el gobierno condiciona, corrige, altera los parámetros naturales y espontáneas del mercado, imponiendo determinadas exigencias con requisitos a la actuación de los agentes económicos ${ }^{62}$.

Sobre este último tema tiene especial relevancia la cláusula social de nuestro actual modelo económico, la cual ha sido interpretada por el TC, quien con meridiana claridad ha señalado que: “[...] dado el carácter 'social' del modelo económico establecido en la Constitución vigente, el Estado no pude permanecer indiferente a las actividades económicas, lo que en modo alguno supone la posibilidad de interferir arbitraria e injustificadamente en el ámbito de libertad reservado para los agentes económicos. [...] En efecto, el modelo de la Economía Social de Mercado [punto medio entre el modelo de la Economía planificada y el modelo de libre mercado] rige nuestro sistema constitucional económico y postula la actuación del Estado en la actividad empresarial, no como interventor, pero sí como regulador ${ }^{63}$.

En estos términos, si bien el Texto Fundamental de 1993 admite que un solo productor satisfaga la demanda de todos los consumidores o usuarios [monopolio], no puede abusarse de dicha posición. Como lo señala LOPEZ DE CASTRO GARCÍA - MORATO, L., Y ARIÑO ORTÍZ, G. en su obra "Derecho de la competencia en sectores regulados: Fusiones y Adquisiciones, control de empresas y poder político", el nuevo modelo de regulación para la competencia consiste en introducir una mayor competencia en aquellos aspectos o actividades en que ésta sea posible y en revisar cómo reformar el sentido de la regulación orientándola a la recreación del mercado.

Esto refleja el difícil equilibrio entre el mercado y la regulación pues la competencia es el objetivo minoritario y la regulación es el instrumento necesario para promover aquella o para crearla cuando no existe llegando hasta sustituirla cuando sea imposible su creación porque existan

${ }^{61}$ Cfr. CASES PALLARÉS, Lluis. "La Competencia en España", Revista Anuarios de la Competencia", Madrid, Marcial Pons, 1998, pp. 15-24, p. 25.

${ }^{62}$ LOPEZ DE CASTRO GARCÍA MORATO Lucía; ARIÑO ORTÍZ, Gaspar. Derecho de la competencia en sectores regulados: Fusiones y Adquisiciones, control de empresas y poder político, Granada, Editorial Comares, 2001, p. 263 y ss.

${ }^{63}$ Ibídem. 
elementos de monopolio natural ${ }^{64}$. En este sentido, la regulación promueve el mercado lo reconstruye, lo defiende, pero no lo sustituye, pues como señala MARTHA O. HESSE la peor tentación del regulador es convertirse en "un gestor en la sombra"65.

LLUIS CACES PALLARES afirma que el rol del Estado en la Economía Social de Mercado se encuentra definido por los principios rectores de la Constitución Económica y por el respeto a los derechos fundamentales del administrado, y por tanto, agrega que la tarea del Derecho Público, y en particular el derecho Administrativo no deben quedar subordinada a las leyes del mercado, sino que debe regular las situaciones que por su naturaleza así lo exigen; esto a pesar que ha existido la ideología de una política conservadora en la que se establece que la riqueza privada fundamental no es sólo una condición necesaria, sino también suficiente de la prosperidad general ${ }^{66}$. Esto permite deducir, que el Estado tiene un rol de primer orden ${ }^{\mathbf{6 7}}$ no sólo en la concreción de las políticas públicas; sino también, y aún más importante, en el respeto de la Constitución de la plena vigencia de los derechos fundamentales del administrado. En este punto, el autor citado agrega que en el marco de un Estado Constitucional y Democrático de Derecho y de un modelo de Economía Social de Mercado, la economía no constituye un fin en sí mismo, sino que es un instrumento al servicio de la persona humana y de su dignidad, razón por la cual el poder económico está limitado por la Constitución, evitando que dicho poder pueda degenerar en un abuso del mismo ${ }^{68}$.

Lo anteriormente afirmado no hace más que fortalecer y materializar lo reconocido por el artículo $58^{\circ}$ de la Constitución de $19 . .$. en el que se identifica, dentro del marco normativo económico, el modelo de una Economía Social de Mercado; de lo que se deriva que, si bien la iniciativa privada es libre, ella no puede ser ejercida en contraposición con el interés general y social $^{69}$.

En este escenario, adquieren especial relevancia las libertades y derechos económicos y el rol del Estado, habida cuenta que el mercado no puede resolver por sí solo, ciertos problemas que aquejan a la sociedad producto de la economía, como son los conflictos sociales que surgen ante la

\footnotetext{
${ }^{64}$ Ibídem.

${ }^{65}$ Cfr. HESSE O., Martha "Regulación del sector eléctrico: objetivos y principios", Revista del Instituto de Estudios Económicos, Nº 4, Octubre 1991, pp. 221-230.

${ }^{66}$ Cfr. CACÉS PALLARES, Luis, Op. Cit.. p. 52.

${ }^{67}$ Cfr. LANDA, César. Op. Cit., p. 52.

${ }^{68}$ Cfr. Ibídem.

${ }^{69}$ Cfr. Ibídem, p 53.
} 
ausencia de mecanismos que permitan una eficiente distribución y redistribución de la riqueza ${ }^{70}$. Más aún, en determinadas circunstancias, ha sido el propio mercado el que ha reclamado la intervención del Estado, pues cuando se diviniza al mercado y la libre competencia, como criterios racionalizadores de la vida productiva [...], lo que intencionalmente se olvida es que el mercado no funcionó nunca sin los correctivos y los apoyos del Estado ${ }^{71}$.

\section{A MODO DE CONCLUSIÓN: DERECHO Y ECONOMÍA: LA RELACIÓN ENTRE EL DEBER DE GARANTIZAR LAS LIBERTADES ECONÓMICAS Y EL ROL REGULADOR DEL ESTADO}

Los principios rectores del orden económico que la Constitución consagra orientan la labor de la Administración Pública en relación a la economía, y resultan relevantes, entre otras razones, porque "las decisiones constitucionales fundamentales son, al tiempo, los valores básicos del Derecho Administrativo"72.

Este modelo constitucional implica el reconocimiento de principios rectores como: Economía Social de Mercado, el Rol subsidiario del Estado, la Libertad de empresa, la Promoción de la libre competencia, el derecho de propiedad y derechos intelectuales, la protección de consumidores y usuarios, los servicios Públicos y Organismos reguladores, el reconocimiento de la Inversión extranjera y libre comercio.

La Economía Social de Mercado como uno de los pilares del marco normativo económico según la Carta Constitucional de 1993, exige que el Estado cumpla una serie de funciones de modo que garantice los derechos fundamentales que ésta reconoce. En este sentido, la Economía Social de Mercado como modelo propio del Estado Social de Derecho busca integrar y conjugar de manera razonable y proporcional la libertad individual y subsidiariedad estatal, y la igualdad y la solidaridad social ${ }^{73}$.

\footnotetext{
${ }^{70}$ Cfr. Ibídem.

${ }^{71}$ DE VEGA, Pedro. "Neoliberalismo y Estado", Pensamiento Constitucional, Año IV, No 4, Lima, Fondo Editorial de la PUCP, 1997, p. 34.

${ }^{72} \mathrm{Sin}$ duda, son éstos principios los que tienen el fundamento antropológico del reconocimiento de la persona humana y el respeto de su dignidad como fin supremo de la sociedad y del Estado, así lo reconoce la misma Constitución en su cuerpo normativo Constitución Política del Perú de 1993. Artículo $1^{\text {o }}$. Cfr. ACHTERBERG. Citado por SHIMIDT-ASSMANN, Eberhard. Op. Cit., p. 51.

${ }^{73}$ Cfr. GONZALES MORENO, Beatriz. El Estado Social. Naturaleza jurídica y estructura de los derechos sociales. Madrid, Civitas, 2002, pp. 102-106; KRESALJA, Baldo; OCHOA, César. Propuesta para un nuevo régimen económico constitucional. En Pensamiento constitucional, No 06, MDC-Fondo Editorial de la PUCP,
} 
No obstante, esta función-deber exige que su cumplimiento se efectúe en base a una serie de principios que el mismo ordenamiento consagra, siendo que si bien las libertades que se han reconocido a favor de los ciudadanos no son plenas, la potestad del Estado para intervenir en materia económica tampoco es irrestricta. Esto sin duda convertirá el escenario de la economía peruana en un mercado competitivo orientado a una mejor asignación de recursos que maximice el bienestar social.

En síntesis resulta necesario que el Estado, en ejercicio de su función reguladora adopte técnicas legislativas que se orienten a promover una competencia eficiente y a crear un país orientado al progreso, a fin de estabilizar las fuerzas de los agentes que entran en el mercado. Sin embargo, ésta no es una tarea fácil, dado que el Estado tiene una exigencia adicional, esto es, debe regular sin transgredir, fiscalizar sin perturbar, vigilar sin obstruir, e intervenir sin destruir, es decir debe guardar proporcionalidad y gradualidad en el ejercicio de la función legal de control y vigilancia, optimizando su gestión.

1999, p. 738. De forma genérica, los autores citados recuerdan de que el reconocimiento de este principio implica la búsqueda de un bienestar mínimo para todos los ciudadanos a través de las reglas del mercado, donde si bien la iniciativa privada [vinculada a la libertad de empresa] sigue siendo fundamental, también debe cumplirse la función social que coadyuve al Estado a lograr el bien común, construyendo una sociedad solidaria. 


\section{BIBLIOGRAFÍA}

- ARBÓS, Eulàlia. [Editor] Atlas de Economía. El comercio en la era global, España, Parramón Ediciones, 2010, pp. 38-49

- BENAVIDEZ GÓMEZ, Leandro. Economía Política General, Pamplona, Universidad de Navarra, 1968.

- BERNALES BALlESTEROS, Enrique. La Constitución de 1993. Comentarios, $5^{\circ}$ Edición, Lima, Editora RAO SRL, 1999.

- BODO, Herzog. "60 años de Economía Social de Mercado: pasado, presente y futuro” en Serie de $N^{o} 01$ de Economía Social de Mercado, № 01, Vol. 01, Fundación Konrad Adenauer, Guatemala, 2009, pp. 9-14.

- CASES PALLARÉS, Lluis. "La Competencia en España” En Revista Anuarios de la Competencia", Madrid, Marcial Pons, 1998, pp. 15-24, p. 25.

- DE VEGA, Pedro. "Neoliberalismo y Estado". En Pensamiento Constitucional, Año IV, N 4, Lima, Fondo Editorial de la PUCP, 1997, p. 34.

- DOMINIK H. Ernste. "Una perspectiva ordoliberal de la Economía Social de Mercado. Basado en los "Principios de política económica" de Walter Eucken [Traducción] En Serie de Economía Social de Mercado, № 02 Vol. 01, Fundación Konrad Adenauer, Guatemala, 2009, pp. $45-59$

- GONZALES MORENO, Beatriz. El Estado Social. Naturaleza jurídica y estructura de los derechos sociales. Madrid, Civitas, 2002, pp. 102-106;

- GUZMAN NAPURÍ, Christian. Introducción al Derecho Público Económico. Lima, Ediciones Caballero Bustamante, 2009

- HABERLE, Peter. "Siete tesis para una teoría constitucional del Mercado". En Revista de Derecho Constitucional Europeo [ReDCE], No 5, Junio 2006, traducido Epor Miguel Azpitarte Sánchez, pp. 11-30, p. 41.

- HERAS ZÁRATE, Luis Henry "La autonomía privada en las regulaciones de la Banca: transportando fundamentos filosóficos" En La persona en el Derecho Peruano. Un análisis jurídico contemporáneo. EMEDECOSEGE, Lambayeque, 2010, pp. 293-309.

- HESSE O., Martha "Regulación del sector eléctrico: objetivos y principios" en Revista del Instituto de Estudios Económicos, № 4, Octubre 1991, pp. 221-230.

- FERNÁNDEZ SESSAREGO, Carlos. "El supuesto de la denominada 'autonomía de la voluntad",. En Contratación Contemporánea- Teoría general y principios. Lima - Bogotá: Palestra - Temis, 2000, p. 254 
- GAllegOS MOLINA, Luis. Economía Social de Mercado, Medio Ambiente y Responsabilidad Social Empresarial, Lima, Impresiones de Tarea Asociación Gráfica Educativa, 2008, pp. 12-13

- GIMENO FELIÚ, José María. "Sistema Económico y Derecho a la libertad de empresa versus reserva al sector público de actividades económicas" En Revista de Administración Pública, $\mathrm{N}^{\mathrm{o}}$ 135, Madrid, 1994, pp. 194-212.

- JÜRGEN RÖSNER, Hans. "Crisis financiera: Redescubrimiento de la Economía Social de Mercado" en Serie de Economía Social de Mercado, N ${ }^{\circ}$ 02, Vol. 01, Fundación Konrad Adenauer, Guatemala, 2009.

- KRESALJA, Baldo; OCHOA, César. Propuesta para un nuevo régimen económico constitucional. En Pensamiento constitucional, Nº 06, MDC-Fondo Editorial de la PUCP, 1999

- KRESALJA, Baldo; OCHOA César. Derecho Constitucional Económico, Lima, Fondo Editorial de la Universidad Católica del Perú, 2009

- LANDA ARROYO, César. Principios rectores y derechos fundamentales del administrado en el marco de la Constitución Económica de 1993. En Revista de Jurisprudencia y Doctrina: Constitución Económica del Perú - Foro Económico Asia - Pacífico [APEC]. Año III, Nº6, 2008

- LOPEZ DE CASTRO GARCÍA MORATO Lucía; ARIÑO ORTÍZ, Gaspar. Derecho de la competencia en sectores regulados: Fusiones y Adquisiciones, control de empresas y poder político, Granada, Editorial Comares, 2001, p. 263 y ss.

- MONTOYA CHÁVEZ, Víctor Hugo. "La configuración jurisprudencial del constitucionalismo económico". En Revista de Jurisprudencia y Doctrina: Constitución Económica del Perú Foro Económico Asia - Pacífico APEC]. Año III, No 06, 2008.

- MÜLLER-ARMACK, Alfred. "Economía Social de Mercado" en Economía Social de Mercado: un proyecto económico y político alternativo. Buenos Aires, Ciedla, 1983

- OCHOA CARDICH, César. Jurisprudencia Constitucional Económica, Ediciones Caballero Bustamante, Lima, 2011

- RIVADENEIRA FRISCH, Juan. Economía Social de Mercado, Ediciones de la Fundación Konrad Adenauer, Quito, 2009, pp 7-9

- SILVA PENEDA, José A. "La Economía Social de Mercado en la Unión Europea” en Serie de $N^{o} 01$ de Economía Social de Mercado, № 01, Vol. 01, Fundación Konrad Adenauer, Guatemala, 2009, pp. 31-43.

- SHIMIDT-ASSMANN, Eberhard. La teoría general del Derecho Administrativo como sistema Instituto Nacional de Administración Pública. Madrid, Marcial Pons, 2003 
- SMITH, Adam. Investigación sobre la naturaleza y causa de la riqueza de las naciones, $2^{\circ}$ Edición, $16^{\circ}$ reimpresión, México, Fondo de Cultura Económica Ltda, 2008

- STC del 10 de agosto del 2009. Expediente N 03116-2009-PA/TC-LIMA. Cementos Lima contra Ministerio de Economía y Finanzas [MEF].

- STC del 28 de marzo del 2009. Expediente No 04466-2007-PA/TC. Empresa de Transporte y Servicios Amauta S.A.C contra la Municipalidad Distrital de Comas, solicitando que se declare inaplicable la Ordenanza Municipal N. ${ }^{\circ}$ 178-2005-C/MC.

- $\quad$ STC del 23 de Febrero del 2006. Expediente N. ${ }^{\text {7 } 7320-2005-P A / T C . ~ E m p r e s a ~ d e ~ T r a n s p o r t e s ~ y ~}$ Turismo Pullman Corona Real S.R.L. contra el Ministerio de Transportes y Comunicaciones a fin de que se declare inaplicable el Decreto Supremo N. ${ }^{\circ}$ 006-2004-MTC, del 20 de febrero de 2004

- STC del 11 de Julio del 2005. Expediente $N^{\circ}$ 3330-2004-AA/TC. Recurso extraordinario interpuesto por don Ludesminio Loja Mori contra la Municipalidad Metropolitana de Lima, la Dirección Municipal de Comercialización y Defensa del Consumidor, y la Dirección de Fiscalización y Control de la Municipalidad Metropolitana de Lima.

- STC del 26 de abril de 2004. Expediente No 018 - 2003 - AI / TC. Jorge Power ManchegoMuñoz, en representación de más de cinco mil ciudadanos contra el Congreso de la República. Solicita la declaratoria de inconstitucionalidad del artículo $1^{\circ}$ de la Ley $\mathrm{N} .{ }^{\circ} 27633$, modificatoria de la Ley N. ${ }^{\circ}$ 27143, Ley de Promoción Temporal del Desarrollo Productivo Nacional.

- STC del 11 de Noviembre del 2003. Expediente $\mathrm{N}^{\mathrm{o}}$ 0008-2003-AI/TC. Acción de inconstitucionalidad interpuesta por don Roberto Nesta Brero, en representación de 5,728 ciudadanos, contra el artículo $4^{\circ}$ del Decreto de Urgencia N. ${ }^{\circ} 140-2001$.

- TORRES VÁSQUEZ, Aníbal. Acto Jurídico, 2ºdición, IBÍDEMSA, Lima, 2001, p. 121.

- VARDÚ, Pablo Lucas. "Los títulos Preliminar y Primero de la Constitución y la interpretación de los derechos y libertades fundamentales". En Revista de la Facultad de Derecho de la Universidad Complutense $\mathrm{N}^{\circ}$ 02, Madrid, 1979.

- WIEMEYER, Joachim. "Crisis del Sistema Financiero: ¿Crisis de la Economía Social de Mercado? En Serie de Economía Social de Mercado, №2 Vol. 01, Fundación Konrad Adenauer, Guatemala, 2009, pp. 25-43. 